1 Wilder HC. Nematode endophthalmitis. Trans Am Acad Ophthalmol Otolaryngol 1950; 55: 99-109.

Duguid IM. Chronic endophthalmitis due to Toxocara Brf Ophthalmol 1961; 45: 705-17.

3 Duguid IM. Features of ocular infestation by Toxocara. Brf Ophthalmol 1961; 45: 789-96.

4 Asthon N. Larval granulomatosis of the retina due to Toxocara. Brf Ophthalmol 1960; 44: 129-48.

5 Wilkinson CP, Welch RB. Intraocular Toxocara. Am $\mathcal{f}$ Ophthalmol 1971; 71: 921-30.

6 Pollard ZF, Jarrett WH, Hagler WS, Allain DS, Schantz PM. ELISA for diagnosis of ocular toxocariasis. Ophthalmology 1979; 86: 743-9.
7 Biglan AW, Glickman LT, Lobes LA. Serum and vitreous Toxocara antibody in nematode endophthalmitis. Am $\mathcal{J}$ Ophthalmol 1979; 88: 898-901.

8 Felberg NT, Shields JA, Federman JL. Antibody to Toxocara canis in the aqueous humor. Arch Ophthalmol 1981; 99: $1563-4$.

9 Shields JA, Lerner HA, Felberg NT. Aqueous cytology and enzymes in nematode endophthalmitis. Am $\mathcal{F}$ Ophthalmo enzymes in nemat

10 Kielar RA. Toxocara canis endophthalmitis with low ELISA titre. Ann Ophthalmol 1983; 15: 447-9.

11 Searl SS, Moazed K, Albert DM, Marcus LC. Ocular toxocariasis presenting as leukocoria in a patient with low ELISA titre to Toxocara canis. Ophthalmology 1981; 88: 1302-6.

\title{
The trap of the displaced blind spot in automated perimetry
}

Neuro-ophthalmology Unit, Geneva University Hospital, Geneva,

Switzerland

A B Safran

G Sunaric

Division of

Endocrinology, Geneva

University Hospital

Geneva, Switzerland

A Burger

Correspondence to:

Professor Avinoam B Safran, Neuro-ophthalmology Unit, Geneva University Hospital, 1211 Geneva 4, Switzerland.

Accepted for publication

6 January 1993

\section{Avinoam B Safran, Gordana Sunaric, Albert Burger}

In routine computer programs used with automated perimetry, restriction in the number of tested locations results in poor spatial delineation of the blind spot. To avoid an inadequate interpretation of the recorded data, a number of computer programs ${ }^{1}$ exclude the evaluation of points located within the presumed area of the blind spot and its surroundings. These programs leave an empty space in the corresponding area of the result printouts.

This solution is advantageous in most clinical settings. With marked cyclotorsion, however,

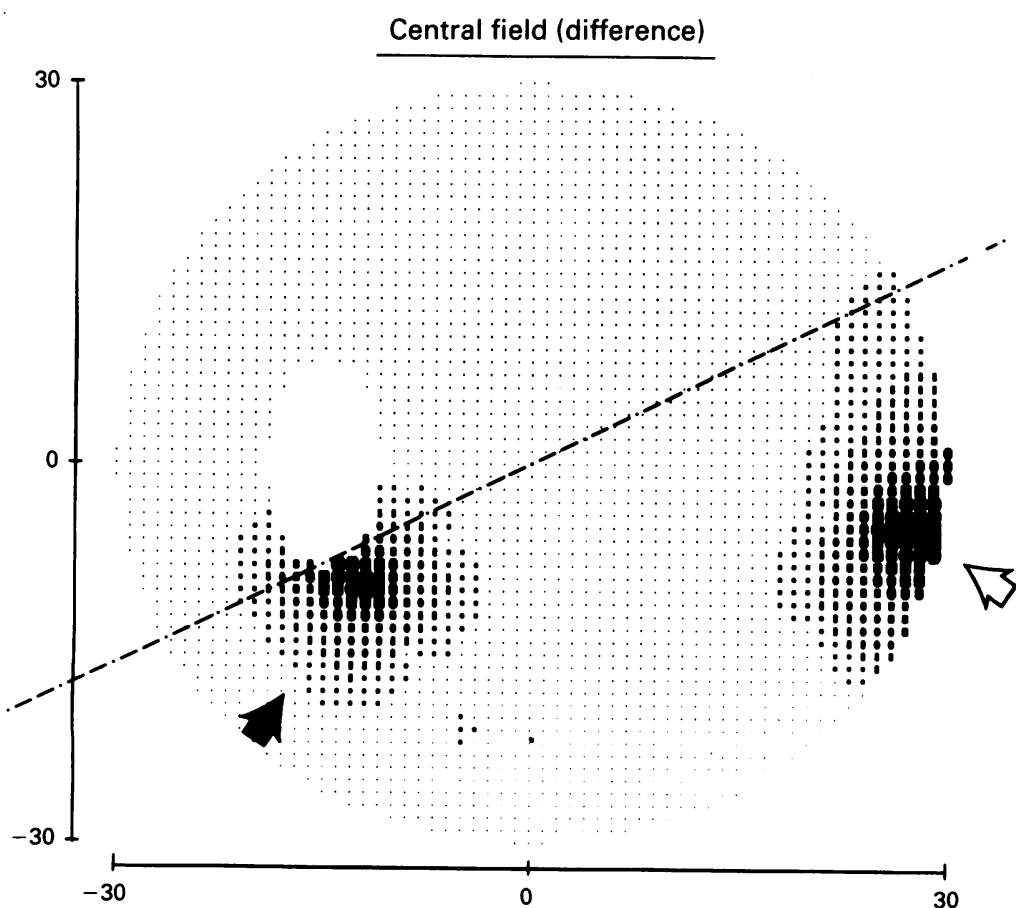

Figure 1 Left visual field, evaluated using automated perimetry. It demonstrated an inferonasal defect (open arrow), and a displaced, enlarged blind spot (closed arrow), and this is mimicking a profoundly altered area within the bundle defect. Broken line shows the projection of the papillomacular axis into the visual field, as inferred from fundus evaluation. the blind spot is displaced to such an extent that it appears in the evaluated portion of the visual field. The condition may be confusing when it occurs in conjunction with a bundle defect, mimicking an absolute scotoma within the area of the nerve fibre defect. This was shown with a patient suffering from Graves' disease which resulted in severe excyclotorsion and optic neuropathy in the same eye.

\section{Case report}

A 57-year-old woman presented with endocrine orbitopathy. Corrected visual acuity was 20/20 in the right eye and 20/25 in the left eye. Relative afferent pupillary defect was found in the left eye. With the patient's head carefully placed in a straight position against the rests, Octopus automated perimetry was performed using the $30^{\circ}$ option of the $\mathrm{N} 1$ program $^{2}$ (Interzeag AG, Schlieren, Switzerland). In the right eye, visual field was unremarkable. In contrast, in the lef eye, the examination showed nasal defects, and a dense scotoma at the inferonasal border of the unchecked area of the blind spot (Fig 1). In that eye, Goldmann kinetic perimetry showed an inferior nasal step; in addition, the blind spot was located some $20^{\circ}$ below its usual position, indicating that the absolute scotoma observed with automated perimetry represented a displaced blind spot. Left fundus showed a $25^{\circ}$ excyclotorsion (Fig 2). Ocular motility was impaired in both eyes, with reduction in elevation and abduction. Exophthalmometry was recorded as 14-14/107. Ocular pressure was markedly increased when attempting upgaze.

\section{Comment}

Displacement of the blind spot has been described in eyes with cyclotorsion. ${ }^{3}$ However, no emphasis has been given to the confounding 


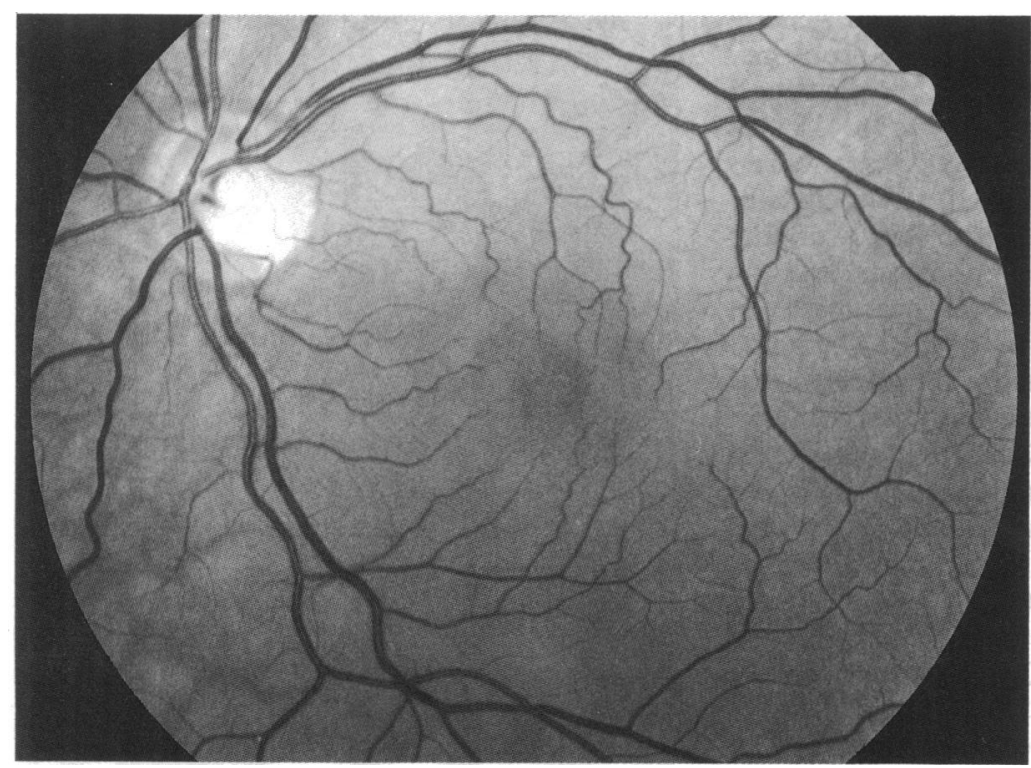

Figure 2 Left fundus, showing $25^{\circ}$ excyclotorsion. effects resulting from the association of blind spot displacement and bundle defects, when using computer programs excluding the testing of the presumed area of the blind spot, and letting the clinician believe that the blind spot is located within the unchecked surface of the visual field.

Examination of the fundus provides valuable information about the degree of cyclotorsion. Doubtful perimetric findings should be checked, using either manual kinetic perimetry or program options for automated perimetry which are specifically designed for evaluation of the blind spot area. ${ }^{24}$

This study was supported in part by the Swiss National Fund for Scientific Research, grant No 32.27842,89.

1 Werner EB. Manual of visual fields. New York: Churchill Livingstone, 1991: 39-89.

2 Safran AB, Mermoud C. A neuro-ophthalmological global analysis program (N1) developed with the Octopus measurement unit. In: Heijl A, ed. Périmetry update 1988/1989. Amsterdam: Kugler, 1989: 151-5.

3 Locke JC. Heterotopia of the blind spot in ocular vertica muscle imbalance. Am $\mathcal{F}$ Ophthalmol 1968; 65: 362-74.

4 Safran AB, Almeida E, Mermoud C, Desangles D, de Weisse C, Lang R. Intraocular and interocular variability of blind spot surface measurements by means of automated perimetry. In: Mills RP, Heijl A, eds. Perimetry update 1990/1991. Amsterdam: Kugler, 1991: 409-12.

\title{
IgG- $x$ extramedullary plasmacytoma of the conjunctiva and orbit
}

\author{
Kazuaki Tetsumoto, Hiroshi Iwaki, Masanori Inoue
}

A rare case of primary extramedullary plasmacytoma of the conjunctiva and orbit is reported. The patient was a 78-year-old woman who presented with tumour of subconjunctiva and orbit in the left eye.

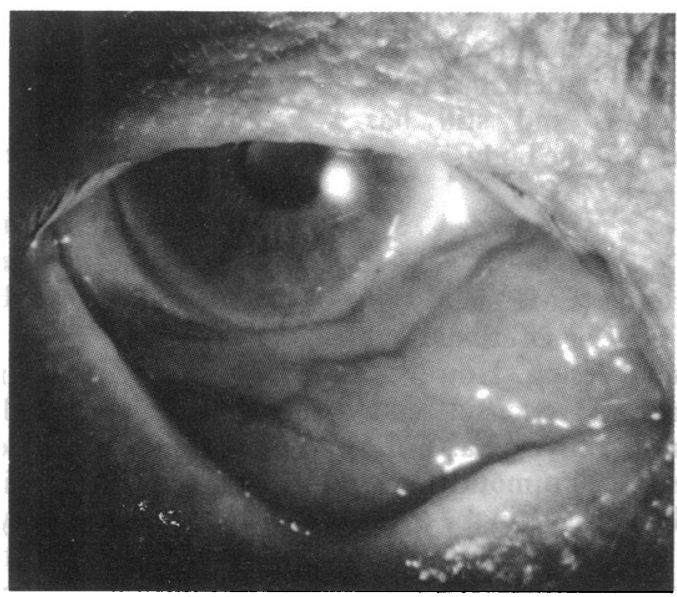

Figure 1 Facial view showing left-sided conjunctival tumour.

\section{Case report}

A 78-year-old woman was referred on 22 October 1990 with a hard mass of the left lower conjunctiva, first noticed 2 months previously and gradually increasing in size. No history of

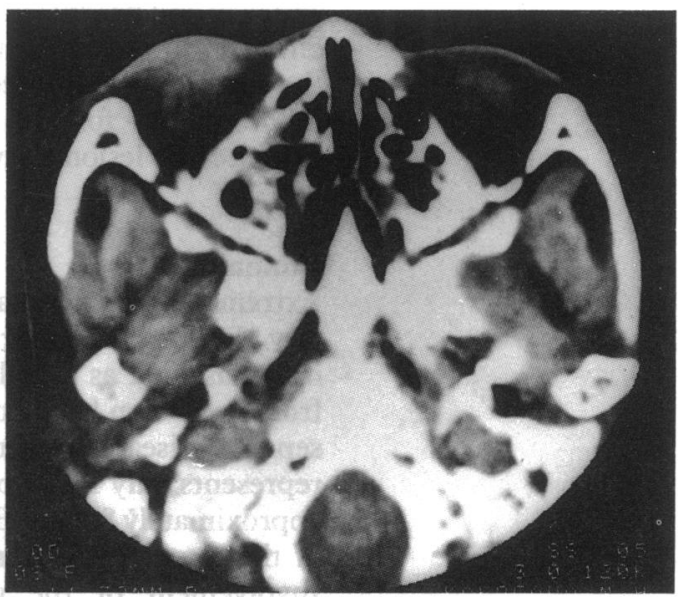

Figure 2 Computed tomography scan: horizontal section through orbit revealing a high density area in the left orbit.

\section{Accepted for publication Accepted for publica \\ Department of Ophthalmology, Kobe Japan \\ K Tetsumoto \\ M Inoue \\ Correspondence to: Dr Rosai Hospital, Kagoike-dor}

